\title{
Acoustic Analysis of / $/$ / and /ð/ Sounds in Pakistani English
}

\author{
Muhammad Asim Mahmood \\ Assistant Professor, Department of Applied Linguistics \\ Government College University, Faisalabad, Pakistan \\ Tel: 0092-41-922-0158Ｅ-mail: masimrai@gmail.com \\ Muhammad Asghar \\ Lecturer, Government College of Science, Faisalabad, Pakistan \\ Tel: 0092-41-265-7535 E-mail: ma291b@gmail.com
}

Farhat Jabeen

M.Phil (scholar), Department of Applied Linguistics

Government College University, Faisalabad, Pakistan

Tel: 0092-346-887-8269Ｅ-mail:farhat2iub@gmail.com

Received: June 7, 2011 Accepted: June 28, $2011 \quad$ Published: November 1, 2011

doi:10.5539/ies.v4n4p131 URL: http://dx.doi.org/10.5539/ies.v4n4p131

\begin{abstract}
This paper aims at discovering the nature and extent of deviation in the articulation of consonants in Pakistani English due to the impact of mother tongue. A detailed experiment has been carried out with the help of Praat to analyze the acoustic properties of $/ \theta /$ and $/ \delta /$ sounds spoken by Pakistani speakers. The research reveals that Pakistani English has a distinct pronunciation pattern of $/ \theta /$ and $/ \delta /$ sounds. This research is an attempt to provide a scientific justification to establish Pakistani English as an independent variety.
\end{abstract}

Keywords: Acoustic analysis, Consonant, Pronunciation pattern, Deviation, Mother tongue, Pakistani English

\section{Introduction}

Urdu is the national language of Pakistan. Punjabi, Sindhi, Pashto and Balochi are some of the major regional languages here. English is used as a second language throughout the country. English spoken by the speakers of different areas is naturally influenced by the linguistic features of the mother tongue (Schneider 2004). It is generally observed that there are certain deviations in the pronunciation of Pakistani speakers of English. These deviations are regarded as errors when they are checked in the dictionary or compared with R.P. Various aspects of Pakistani English have been studied by several researchers (Rehman 1990, Baumgardner 1993, Tallat 2003, Schneider 2004, Mahboob and Ahmar 2004a \& 2004b, Anwar 2007) but no systematic, scientific and detailed study of the phonetic and phonology of Pakistani English has yet been attempted.

English is, now, an international language. R.P. is not the elevated standard anymore. The USA, Australia and India have proved that the versions of English spoken in their respective countries constitute separate varieties. In present research, the pronunciation of Pakistani speakers of English has been compared with the Received Pronunciation (R.P.) regarding $/ \theta /$ and $/ \delta /$ sounds. R.P. is chosen for comparative study due to various reasons. Ambercrombie (1965) regarded it as the 'Standard English' within England and he defines it as "that kind of English which is the official language of the entire English speaking world and also the language of all educated English speaking people in England" (p. 10). Moreover, its standard descriptions and teaching materials are easily available.

The present study is 'scientific' as well as 'instrumental' in locating the deviations in Pakistani English regarding / $\theta /$ and / $/$ / sounds spoken by Pakistani speakers. The research has been conducted in the region of Faisalabad but the linguistic features are shared by the majority of educated speakers of Pakistan. The researchers have scientifically analyzed Pakistani English by using PRAAT. It is an attempt towards the codification of Pakistani English.

\section{Literature Review}

People speak different languages and language change is a natural phenomenon. As Ladefoged (2005) says, "Elderly 
people cannot readily understand what their grandchildren are saying, and the same is true in reverse"(p. 2). The English language issued forth from England and expanded over the world rapidly. The expansion of the English language is so tremendous that no other language has such a history of acceptance over such a diverse area. It has become the native tongue of Americans, Australians, and New Zealanders. In former British Colonies like Pakistan, India and Sri Lanka, it is being used as a second language. These speech communities have diverse ethnic, cultural and social compositions and exerted great impact on English over a long period of time.

Trudgill (2004) opines that English has gone through certain changes at syntactic, lexical and phonological levels due to its widespread expansion. These changes have occurred due to interaction of the English language and the native languages. Rajimwale (2006) says, "It is only natural that the spread of a single language over such an extensive and variable region has created such varieties of the language as to appear vastly different from the British English" (p.125). Hung (2000) pointed out various systematic features of phonology of Hong Kong English (HKE) and so tried to prove HKE a separate variety of English. Ali (1994) and Shuja (1995) made remarkable contribution in the discovery of phonetic and phonological deviations in the pattern of Indian English. They conducted research to locate deviations in Indian English but their research was 'impressionistic-articulatory' and not 'instrumental'.

In Pakistan, comprehensive research on Pakistani English has not been conducted yet. Anyhow, efforts have been made on various levels to prove that Pakistani English (PE) is a variety in the making. Rehman (1990) has described the segmental and non- segmental features of the Pakistani English and highlighted differences at lexical level due to the impacts of Islamic culture and historical experiences of Pakistani culture. Baumgardner (1993) comments that $\mathrm{PE}$ is not a standard variety, rather it is in the process of standardisation. Tallat (2003) observes that the changes in lexical structures of PE are due to code-switching and code-mixing of native languages of Pakistan especially of Urdu. Anwar (2007) is also of the view that code-switching affects PE at the phrase and clause level and it has its own distinctive features. Mahboob and Ahmar (2004a) worked on the pronunciation patterns in Pakistani English $(\mathrm{PE})$ and pointed out various variations in pronunciation due to the impact of native language.

Previous research on Pakistani English has explored various levels of syntax, morphology, phonology and cod-mixing pointing out some of its distinct features. The researchers seem to agree at a point that Pakistani English is emerging as an independent variety of English.

\section{Methodology}

\subsection{Research Design}

In the present research, the mixed method was used. The triangulation of qualitative and quantitative method was used to establish the validity of the research. Some words of English and Urdu were selected to analyze the $/ \theta /$ and $/ \delta /$ sounds spoken by Pakistani speakers on all the three positions of the word i.e initial, medial and final. The sounds of Pakistani English, R.P. and Urdu words were recorded and the acoustic properties of $/ \theta /$ and $/ \delta /$ sounds were analyzed on the software PRAAT. Their formant values were recorded, compared and analyzed.

\subsection{Data Collection}

i. 25 English words were selected to analyze the $/ \theta /$ and / $/$ sounds, spoken by Pakistani speakers and the British speakers, on all the three positions of initial, medial and final of the words (Insert Table 1).

ii. 18 Urdu words were selected to analyze the /th/ and / d/ sounds spoken by Pakistani speakers on all the three positions of initial, medial and final of the words (Insert Table 2).

\subsection{Data Recording}

PRAAT software was used for recording and acoustic analysis of the sounds.

i. 15 postgraduate students were requested to pronounce the lists of selected words of English and Urdu as mentioned above.

ii. R.P. sounds of the same English words were recorded from the online talking dictionary and BBC News.

\subsection{Data Analysis}

All the data (Pakistani English pronunciation, R.P. pronunciation and Urdu pronunciation) were analyzed on PRAAT separately. The spectrograms of $/ \theta /, / \partial /, /$ th/ and $/ \mathrm{d} /$ sounds were recorded and analyzed.

\subsubsection{Spectrogram Analysis}

Following are some of the representative spectrograms of $/ \theta /$ and / $/$ / sounds of RP, $\theta /$ and / $/$ / sounds of Pakistani speakers of English (PSE) and /th/ and /d/ sounds of Pakistani speakers of Urdu (PSU).

i. On the spectrogram of RP word for $/ \theta$ / sound of the recorded word "think", the value of frequency of F1 was 766 
$\mathrm{Hz}$ and $\mathrm{F} 2$ was $2342 \mathrm{~Hz}$, as shown in Spectrogram of / $/ \theta /$ (R.P.) No.1.

ii. On the spectrogram of RP word for / $/ \mathbf{~}$ / sound of the recorded word "thy", the value of frequency of F1 was 863 $\mathrm{Hz}$ and F2 was $1390 \mathrm{~Hz}$, as shown in Spectrogram of /ð/ (R.P.) No.2.

iii. On the spectrogram of Pakistani English for $/ \theta$ / sound of the recorded word "think", the value of frequency of $F 1$ was $589 \mathrm{~Hz}$ and F2 was $1996 \mathrm{~Hz}$, as shown in Spectrogram of /9/ (PSE) No.3.

iv. On the spectrogram of Pakistani English for / $\mathbf{0}$ / sound of the recorded word "thy", the value of frequency of F1 was $467 \mathrm{~Hz}$ and F2 was $1351 \mathrm{~Hz}$, as shown in Spectrogram of /ð/ (PSE) No.4

v. On the spectrogram of Urdu word for /th/ sound of the recorded word "thap", the value of frequency of F1 was $668 \mathrm{~Hz}$ and F2 was $1468 \mathrm{~Hz}$, as shown in Spectrogram of /th/ (PSU) No.5.

vi. On the spectrogram of Urdu word for /d/ sounds of the recorded word "dil", the value of frequency of F1 was $355 \mathrm{~Hz}$ and F2 was $1933 \mathrm{~Hz}$, as shown in Spectrogram of /d/ (PSU) No.6.

\subsubsection{Average Values:}

The average values of frequencies of their formants of F1and F2 were collected and compared (Insert Table 3).

\section{Discussion}

i. Ladefoged (2005) and Sethi \& Dhamija (1994) explain that articulation of consonant phonemes of $/ \theta /$ and / / sounds is "Dental Fricatives". RP spectrograms on PRAAT also confirm this reality by showing thickness and high frequency of formants F1 and F2. On the spectrograms of RP words for $/ \theta /$ sounds of the recorded 15 words, the average value of frequency of F1 was $993 \mathrm{~Hz}$ and F2 was $2197 \mathrm{~Hz}$. Similarly, on the spectrograms of RP words for $/ \widetilde{d} /$ sounds of the recorded 10 words, the average value of frequency of F1 was $882 \mathrm{~Hz}$ and F2 was $1406 \mathrm{~Hz}$ (Table $3)$.

ii. The PRAAT analysis of $/ \theta /$ and $/ \delta /$ sounds spoken by Pakistani speakers pointed out that thickness is low and frequencies of formants are considerably low as compared to RP sounds. On the spectrograms of Pakistani English for $/ \theta /$ sounds of the recorded 225 words, the average value of frequency of F1 was $550 \mathrm{~Hz}$ and F2 was $1805 \mathrm{~Hz}$. Similarly, on the spectrograms of Pakistani English for / $\mathbf{d} /$ sounds of the recorded 150 words, the average value of frequency of F1 was $465 \mathrm{~Hz}$ and F2 was $1438 \mathrm{~Hz}$ (Table 3). So, consonant phonemes of / $/$ / and /ठ/ sounds spoken by Pakistani speakers are dissimilar from that of R.P. They are "Dental Plosives" instead of "Dental Fricatives".

iii. Ali (1994) and Shuja (1995) described/th/ and /d/ sounds of Urdu words as "Dental Plosives. The Praat analysis of $/ \mathrm{th} /$ and $/ \mathrm{d} /$ sounds of Urdu words pointed out that thickness is low and frequencies of formants are also low. On the spectrograms of Urdu words for /th/ sounds of the recorded 135 words, the average value of frequency of F1 was $583 \mathrm{~Hz}$ and F2 was $1556 \mathrm{~Hz}$. Similarly, on the spectrograms of Urdu words for/d/ sounds of the recorded 135 words, the average value of frequency of F1 was $383 \mathrm{~Hz}$ and F2 was $1883 \mathrm{~Hz}$ (Table 3). Hence, spectrograms by Praat also confirm this reality that they are "Dental Plosives. The place and manner of articulation of $/ \theta /$ and $/ \delta /$ sounds in Pakistani English seem similar to that of /th/ and /d/ sounds of Urdu words.

\section{Conclusion}

In the light of above mentioned data analysis and discussion, it is quite evident that there is clear indication of deviation in the articulation of consonant phonemes of $/ \theta /$ and $/ \delta /$ sounds in Pakistani English. Their formant values are near to formant values of /th/ and /d/ sounds of Urdu words instead of formant values of RP consonant phonemes of $/ \theta /$ and $/ \delta /$. It means that consonant phonemes of $/ \theta /$ and $/ ð /$ sounds in Pakistani English are dissimilar from RP consonant phonemes of $/ \theta /$ and $/ \delta /$. Their place of articulation is same but manner of articulation is different. Moreover, RP consonant phonemes of $/ \theta /$ and $/ \delta /$ have no counterpart in Urdu at any level. Pakistani speakers of English replace these dissimilar RP consonant phonemes with the phonetically nearest consonant phonemes /th/ and /d/ of Urdu words (Figure $1 \& 2$ ). It is a clear indication of impact of mother tongue on the pronunciation of the Pakistani speakers of English. So, this deviation shouldn't be taken as an error. The consonant phonemes of / $\theta /$ and /ð/ sounds in Pakistani English should be recognized as "Dental Plosives" instead of "Dental Fricatives".

\section{References}

Ali, A. (1994). Phonological patterns in Urdu speakers'English. New Dehli: Bahri Publications.

Ambercrombie, D. (1965). Studies in phonetics and linguistics. London.

Anwer, B. (2007). Urdu-English code-switching: The use of Urdu phrases and clauses in Pakistani English (a non-native variety). ESP World. 6(3), 16, [Online] Available: http://esp-world.info/Articles_16/issue_16.htm (September 17, 2010) 
Baumgardner, J. (1993). The indigenization of English in Pakistan. In J. Baumgardner, The English language in Pakistan, 41-54. Karachi: Oxford University Press.

Hung, T. (2000). Towards the phonology of Hong Kong English. World Englishes, 19(3), 337-356. doi:101111/1467-971x.00i83, http://dx.doi.org/101111/1467-971x.00i83

Ladefoged, P. (2005). Vowels and consonants. USA: Blackwell.

Mahboob, A., \& Ahmar, N. (2004a). Pakistani English: Phonology. In E. B. Schneider, et al. (Eds.), $A$ hand book of varieties of English, 1, 1003-1016. Berlin. [Online] Available: http://books.google.com.pk (August 10, 2010)

Mahboob, A., \& Ahmar, N. (2004b). Pakistani English: Morphology \& syntax. In E. W. Schneider, et al. (Eds.), $A$ hand book of varieties of English, 2, 1045-1057. Berlin. [Online] Available: http://books.google.com.pk (August 10, 2010)

Rajimwale, S. (2006). Elements of general linguistics. India: Rama Brothers.

Rahman, T. (1990). Pakistani English: The linguistic description of a non-native variety of English. Islamabad: National Institute of Pakistan Studies, Quaid-e-Azam University.

Schneider, E. W. (2004). Global synopsis: Phonetic and phonological variation. In E. W. Schneider, et al. (Eds.), English world-wide, 1111-1137

Sethi. J., \& Dhamija. P. V. (1994). A course in phonetics and spoken English. India: Prentice-Hall.

Shuja, A. (1995). Urdu-English phonetics and phonology. New Delhi: Bahri Publications.

Tallat, M. (2003). Pakistani English: A sociolinguistic variety. Journal of Research, 4, 17-30

Trudgil, P. (2004). New-dialect formation: The inevitability of colonial Englishes. Edinburgh: Edinburgh University Press.

Table 1. Data Collection

\begin{tabular}{|c|c|c|c|c|}
\hline Initial $\quad / \theta /$ & Medial $/ \theta /$ & Final $/ \theta /$ & Initial /ð/ & Medial /ð/ \\
\hline Think & Ethic & Math & There & Mother \\
\hline Theme & Author & Tooth & Them & Father \\
\hline Thorough & Ether & Earth & Though & Either \\
\hline Thematic & Catholic & Worth & Thy & Rhythm \\
\hline Thing & Bathing & Death & That & Feather \\
\hline
\end{tabular}

25 English words were selected to analyze the $/ \theta /$ and / $/$ / sounds, spoken by Pakistani speakers and the British speakers, on all the three positions of initial, medial and final of the words. 
Table 2. Data Collection

\begin{tabular}{|c|c|c|c|c|c|}
\hline Initial $/ \mathrm{t}^{\mathrm{h}} /$ & Medial $/ \mathrm{t}^{\mathrm{h}} /$ & Final $/ \mathrm{t}^{\mathrm{h}} /$ & Initial /d/ & Medial / / $/$ & Final /d $/$ \\
\hline Thap & Matha & Hath & Dil & Sady & $\mathrm{Bad}$ \\
\hline thal & Hathy & Sath & Dana & Mady & Khad \\
\hline tham & Sathy & Nuth & Dus & Jadu & Saad \\
\hline
\end{tabular}

18 Urdu words were selected to analyze the /th/ and /d/ sounds spoken by Pakistani speakers on all the three positions of initial, medial and final of the words.

Spectrogram of /ө/ (R.P.) No. 1 RP- / $\theta$ / of think ,F1\# 766 Hz, f2\# $2342 \mathrm{~Hz}$, time=0.027

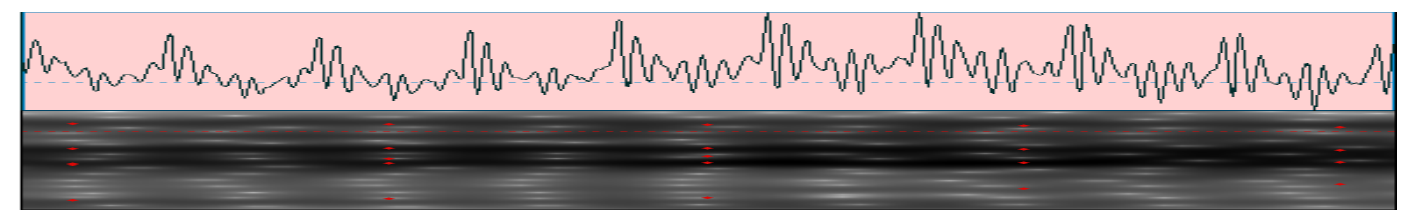

Spectrogram of /ð/ (R.P.)- No. 2 /ð/ of thy ,F1\# 863 Hz, f2\# 1390 Hz, time=0.158

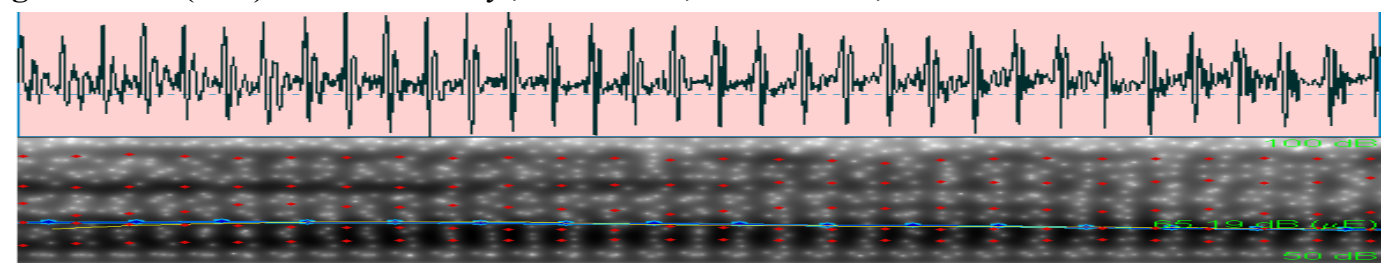

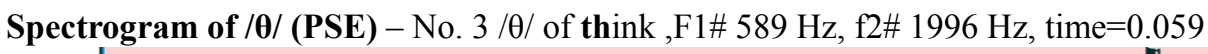

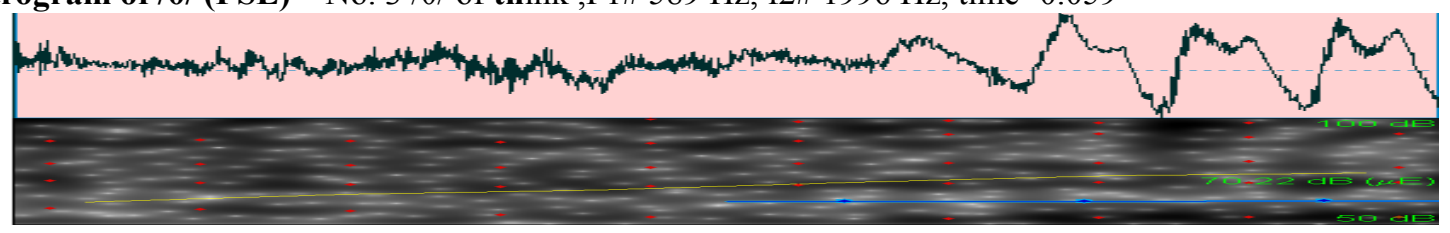

Spectrogram of / ð / (PSE) - No. 4 /ð/ of thy ,F1\# $467 \mathrm{~Hz}$, f2\# $1351 \mathrm{~Hz}$, time=0.0366

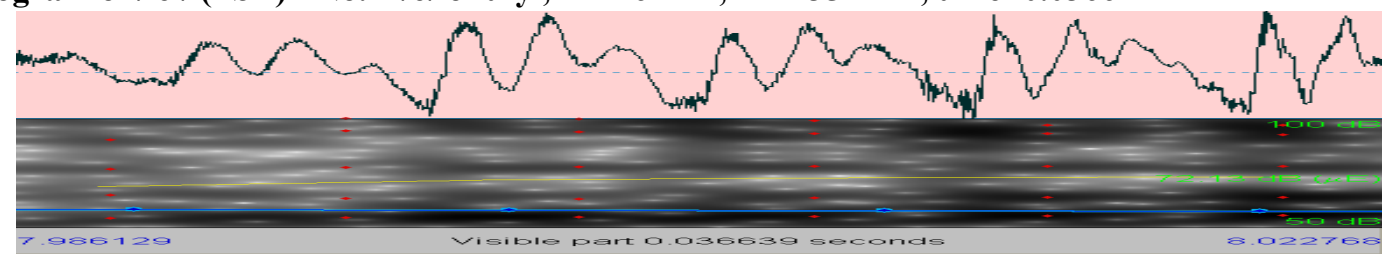

Spectrogram of $/ \mathrm{t}^{\mathrm{h}} /$ (PSU)- No. $5 / \mathrm{t}^{\mathrm{h}} /$ of Thap ,F1\# $668 \mathrm{~Hz}$, f2\# $1468 \mathrm{~Hz}$, time=0.079

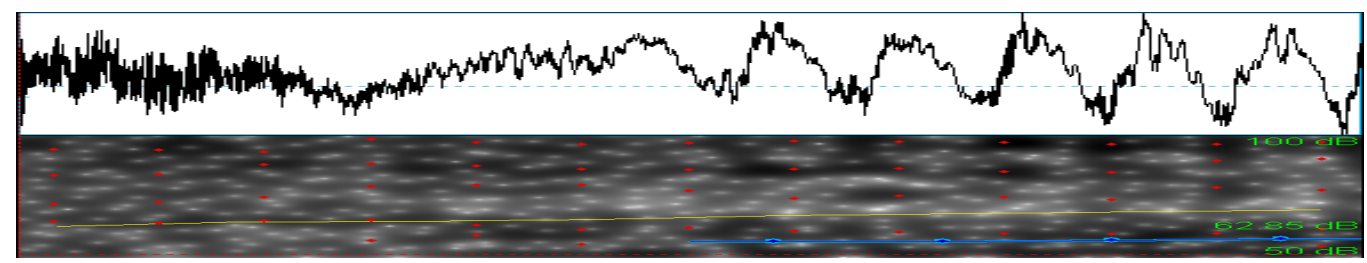

Spectrogram of /d/ (PSU)- No. 6 /d/ / of Dil ,F1\# 355 Hz, f2\# 1933 Hz, time=0.041

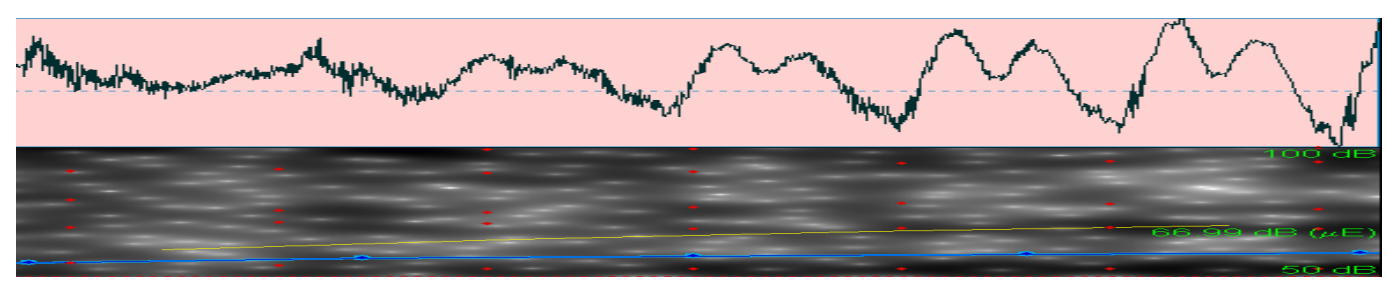


Table 3. Average Values of frequencies of the formants of F1and F2:

\begin{tabular}{|c|c|c|c|c|c|c|}
\hline & $/ \theta /($ R.P.)* & /ð/ (R.P.) & $/ \theta /(\mathrm{PSE}) *$ & /ð/ (PSE) & $/ \mathrm{t}^{\mathrm{h}} /(\mathbf{P S U}) *$ & $/ \mathbf{d} /(\mathbf{P S U})$ \\
\hline F1 Ave. value & 993 & 882 & 550 & 465 & 583 & 383 \\
\hline F2 Ave. value & 2197 & 1406 & 1805 & 1438 & 1556 & 1883 \\
\hline
\end{tabular}

Note: ${ }^{*}$ R.P. $=$ Received Pronunciation of England, PSE $=$ Pakistani speakers of English, PSU =Pakistani speakers of Urdu

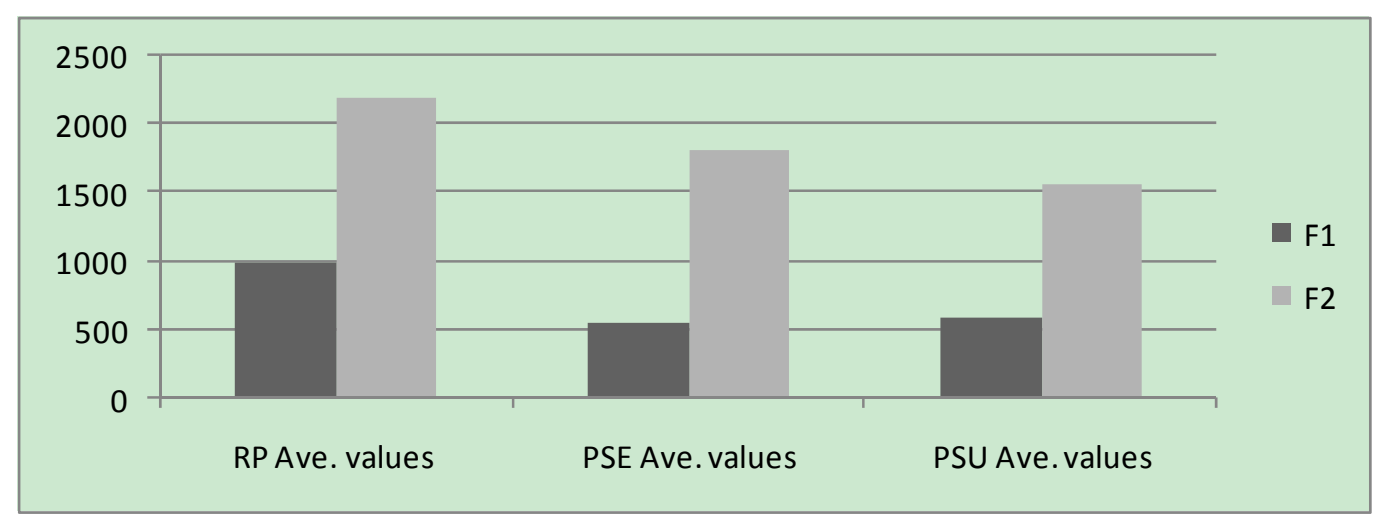

Figure 1. Analysis of $/ \theta /$ Values

Graph analysis of $/ \theta /$ values indicate that the formant values, F1 \& F2, of Pakistani speakers of English (PSE) are near to formant values of $/ t_{x}^{\mathrm{h}} /$ and $/ \mathrm{d} / \mathrm{s}$ sounds of Pakistani speakers of Urdu (PSU) instead of formant values of R.P consonant phonemes of $/ \theta /$ and $/$ ठ/.

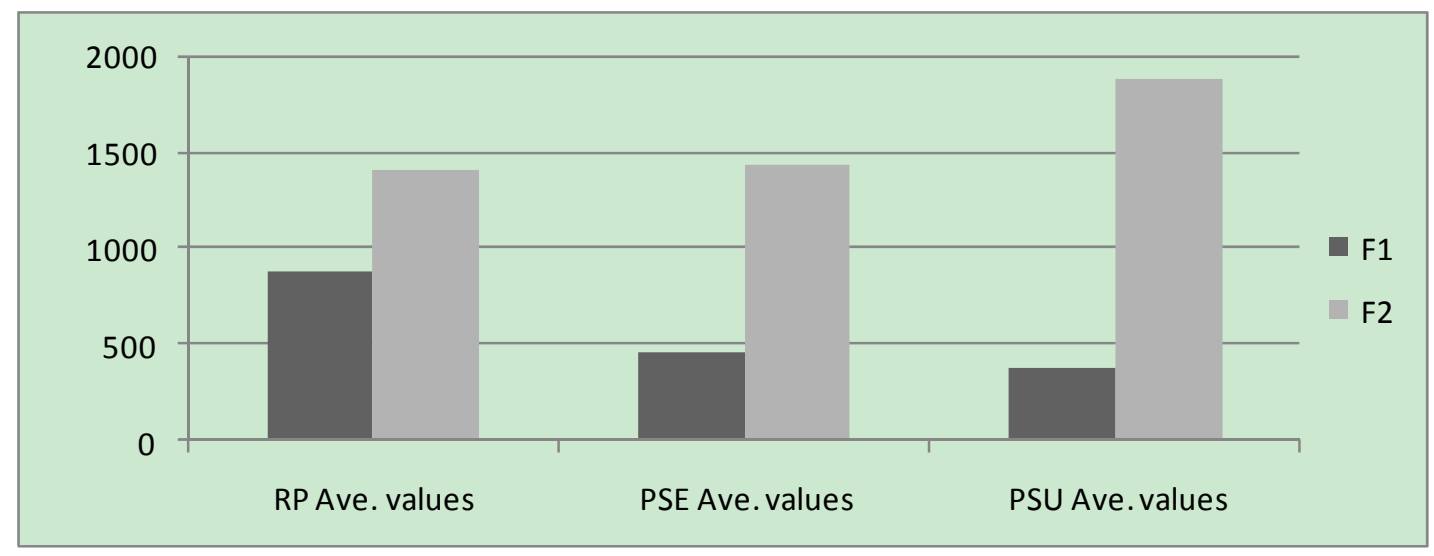

Figure 2. Analysis of /ð/ Values

Graph analysis of /ð/ values indicate that the formant values, F1 \& F2, of Pakistani speakers of English (PSE) are near to formant values of F1 of $/ \mathrm{t}^{\mathrm{h}} /$ and $/ \mathrm{d} / /$ sounds of Pakistani speakers of Urdu (PSU) instead of formant values of R.P consonant phonemes of $/ \theta /$ and $/ ð /$. 